\section{European Psychiatry}

www.cambridge.org/epa

\section{Research Article}

Cite this article: Fossi LD, Debien $C$ Demarty A-L, Vaiva G, Messiah A (2021). Suicide reattempt in a population-wide brief contact intervention to prevent suicide attempts: The Vigilans program, France. European Psychiatry, 64(1), e57, 1-17 https://doi.org/10.1192/j.eurpsy.2021.2221

Received: 04 April 2021

Revised: 04 July 2021

Accepted: 08 July 2021

\section{Keywords:}

prevention; suicide attempts; suicide reattempt; Vigilans

Author for correspondence:

*Larissa D. Fossi,

E-mail: larissa.fossi@inserm.fr (c) The Author(s), 2021. Published by Cambridge University Press on behalf of the European Psychiatric Association. This is an Open Access article, distributed under the terms of the Creative Commons AttributionNonCommercial-ShareAlike licence (http:// creativecommons.org/licenses/by-nc-sa/4.0/), which permits non-commercial re-use, distribution, and reproduction in any medium, provided the same Creative Commons licence is included and the original work is properly cited. The written permission of Cambridge University Press must be obtained for commercial re-use.

\section{Suicide reattempt in a population-wide brief contact intervention to prevent suicide attempts: The VigilanS program, France}

\author{
Larissa D. Fossi ${ }^{1,2 *}$ (D), Christophe Debien ${ }^{3,4}$, Anne-Laure Demarty ${ }^{3}$, \\ Guillaume Vaiva $^{3,4}$ and Antoine Messiah ${ }^{1}$
}

${ }^{1}$ MOODS, INSERM U 1018, CESP, Université Paris-Saclay, Faculté de Médecine Paris-Saclay, Le Kremlin Bicêtre, F-94275, France; ${ }^{2}$ Sorbonne Université, INSERM, Institut Pierre Louis d'Épidémiologie et de Santé Publique, IPLESP, Équipe de Recherche en Épidémiologie Sociale, Paris F75012, France; ${ }^{3}$ Department of Psychiatry, CHU Lille, Lille, France and ${ }^{4}$ Univ. Lille, Inserm, CHU Lille, U1172, LilNCog - Lille Neuroscience \& Cognition, F-59000, Lille, France and Centre national de ressources et de résilience (CN2R), F-59000, Lille, France.

\begin{abstract}
Objective. Among the postcrisis suicide prevention programmes, brief contact interventions (BCIs) have been proven to be efficient. VigilanS generalizes to a whole French region a BCI combining resource cards, telephone calls, and sending postcards, according to a predefined algorithm. However, a major problem in suicide prevention is the suicide reattempt, which can lead to final suicide. Here, we analyze the suicide reattempt in VigilanS.

Methods. The study concerned patients included in VigilanS over the period from January 1, 2015 to December 31,2018, with an end of follow-up on July 1,2019. We performed a series of descriptive analyses, survival curves, and regressions. The outcome was the suicide reattempt, and the predictive variables were the characteristics of the patient at entry and during follow-up in VigilanS. Age and sex were considered as adjustment variables.

Results. A total of 11,879 inclusions occurred during the study period, corresponding to 10,666 different patients, among which 905 reattempted suicide. More than half were primary suicide attempters (53.4\%). A significant relationship with suicide reattempt was identified for the following characteristics: being a non-primary suicide attempter, having attempted suicide by voluntary drug intoxication and phlebotomy, alcohol consumption among primary suicide attempters, and having no companion at the emergency room visit among non-primary suicide attempters. Hanging (as suicide method), having made no call to VigilanS were protective factors.

Conclusion. This study provides us with a valuable insight into the profiles of patients repeating a suicide attempts, which is important for suicide prevention in general.
\end{abstract}

\title{
Introduction
}

According to the World Health Organization (WHO), around 800,000 people die by suicide each year worldwide [1]. Suicide and suicide attempts (SA) are major public health problems, representing an economic burden [2,3] and a great emotional burden, impacting families and relatives. SA are nearly 20 times more common than suicide deaths [4], and history of SA is predictive of subsequent attempts and risk of death by suicide (which typically occurs after several repeated attempts) $[4,5]$. The risk of complete suicide for people who have already had a previous history of SA is higher individuals with a single suicide attempt [6,7]; this risk increases with each SA and remains high for more than 30 years [8]. According to Aresman et al., nearly half of repeat events occur within the first 3 months after the initial attempt and nearly two thirds (64\%) within the first 6 months [9]. The risk of recurrence is highest immediately after discharge from hospital, with one in three patients repeating the attempt within 30 days [10].

It has been shown that the method used in the first SA is an important predictor of subsequent SA [11,12]. A number of studies have found that recurrence rates are higher in people who presented with low lethal methods such as self-cutting, while those who used more lethal methods, such as hanging or drug over dose, had lower recurrence rates [13-15]. Conversely, other studies have found that subsequent SA were more likely to have occurred among people who use high-lethal methods in the index attempt (such as poisoning by domestically used gas, poisoning by other gases and vapors, hanging, drowning, firearms, air guns and explosives, jumping from high places, and other unspecified means) [16].

Given all of these characteristics, the implementation of recidivism prevention techniques is important. Among the many elements to be considered, the recommendations recommend monitoring programs such as maintaining contact at hospital discharge after a SA [17,18]. These monitoring programs are commonly referred to as "brief contact interventions" (BCIs) 
$[19,20]$. These BCIs include: telephone recontact [21], issuing a "resource card" mentioning the call number of a professional crisis manager [22]; sending letters written by a person who met the suicidal patient during a hospital stay [23]; sending postcards [24]; and sending text messages to maintain contact [25]. Several studies have shown the effectiveness of BCIs in reducing SA [26-28]. Bertolote et al. found the efficacy of phone calls on suicide mortality, but did not demonstrate this effect on SA, contrasting with Cebrià et al. who found a decrease in the number of suicide reattempt related to phone calls, agree with those of a study on telephone follow-up as a protective factor against repeated suicide attempt [27,28]. Fleischmann et al. found a significant reduction in death by suicide among suicide attempters, based on continuous communication in combination with standard treatments [26].

In 2015, Milner et al. and Inagaki et al. published simultaneously two meta-analyses evaluating the effect of BCIs on people who have done SA. Their converging findings suggested that patients benefited from recontact procedures, with significantly lower relapse and suicide rates compared to controls treated as usual $[19,20]$. According to the results of Milner et al., BCIs were effective on the number of suicide reattempts per person (incidence rate ratio $=0.66$ ) [19]; according to the meta-analysis of Inagaki et al., BCIs were effective to prevent a repeat suicide attempt at 12 months (relative risk $=0.83$ ) [20].

The well documented effectiveness of BCI procedures, as well as their low cost and ease of deployment, are strong arguments in favor of their integration into a comprehensive multilevel prevention strategy [29]. Furthermore, by taking into consideration the strengths and limitations of each of these strategies (e.g., crisis card had a significant effect for first attempters than others) [21-24], a combination of BCIs has been proposed to allow for flexible and effective implementation $[30,31]$. This is the case of the VigilanS program [32-34].

Created in 2014 in collaboration with the hospitals of Nord-Pas de Calais, and operational since 2015, VigilanS allows to contact any suicidal person immediately after a SA, by a team of mental health professionals specially trained in suicide crises management. It is a regional BCI, combining several interventions: a resource card, telephone calls, and sending postcards [32]. Unlike clinical trials, VigilanS is implemented in the entire population, under real conditions. Studies on BCIs are generally clinical trial studies, but the major disadvantage is the lack of generalization to the whole population, due to significant selection bias [35]. To our knowledge, there is a lack of literature on regionally implemented post-attempt BCIs. Previous studies have been done on VigilanS. These previous studies on VigilanS concerned the description of VigilanS in its functioning and implementation, and the relationship between the variation in SA and VigilanS penetration (proportion of people who had a suicide attempt and were included in VigilanS, relative to all people who had a suicide attempt regardless of their inclusion in VigilanS), in Nord-Pas de Calais hospitals (NPC) [33,34]. Nevertheless, the description of the profile of the patients followed by VigilanS as well as the analysis of suicide reattempt after inclusion in VigilanS are important analyses that have not yet been explored in these previous studies conducted on VigilanS. This is therefore the point of our article.

\section{Objective}

The objective of this article was to study suicide reattempt in patients followed for at least 6 months in VigilanS. More specifically, the aim was to describe the characteristics of the patients, to estimate the mean time between suicidal iterations, and to identify the profiles of patients who had a suicide reattempt compared to other patients.

\section{Methods}

\section{Description of the Vigilans system}

VigilanS is a 6-month monitoring program, after a SA. As soon as the patient is discharged from the emergency room, he or she receives a resource card with the VigilanS number on it. From this point onwards, VigilanS takes charge of the intervention and patients follow-up, which complement the routine care provided by the participating centers, for a 6 -month period.

\section{Telephone calls between the 10th and 21st day (D10-D21)}

Between 10th and the 21st day after discharge from hospital (D10D21), all non-primary suicide attempters are recalled because they are at high risk of doing a new SA. During the D10-D21 call, decisions are made, depending on the case at hand as judged by the calling professional: an emergency or a regular appointment is planned; a new telephone call is scheduled; personalized postcards are sent; these actions can be combined; or no further action is planned.

\section{Six-month calls}

At the 6th month, all patients (primary and non-primary suicide attempters) are called for an end of follow-up interview. A nonprimary suicide attempter is a patient who have done at least one previous SA when included in VigilanS, and a primary suicide attempter is a patient who have done a first suicide attempt when included in VigilanS. Before each call, the patient is informed in advance of the call that will be made. If judged necessary by the calling clinician, the program can be extended for another 3 or 6 months. In case of a new SA during the follow-up period, the entire VigilanS program is reset for another 6 months. If a patient reiterates a SA after the follow-up period, (s)he re-enters VigilanS. There is no limit on the number of entries.

\section{Other telephone calls during follow-up}

In addition to these two systematic calls, intermediate calls are also made during the 6-month follow-up period. Intermediate calls are calls made at the initiative of VigilanS (outgoing calls) outside the two calls provided for by the program (at D10-D21 and at 6 months), or calls made by patients (incoming calls). A detailed description of the VigilanS intervention is published for more information [32,33].

\section{Patient selection}

Our study was conducted on all the patients included in VigilanS over the period from January 1, 2015 to December 31, 2018 in the Nord-Pas-de-Calais region. July 1, 2019 marks the end of the follow-up of our study. Patients who died during the first stay follow-up (before the second inclusion in VigilanS) were excluded from the analysis.

\section{Data processing}

The same patient can be included several times in VigilanS in case of repeated SA. Therefore, the statistical units of analysis (SUA) can be either the SA that triggered an inclusion in VigilanS, with 
possibly several records per patient, or the patients, with a single record consisting of all successive inclusions, if any. For our study, the statistical units were the patients; for those who had multiple inclusions in VigilanS, the first inclusion was selected.

\section{Statistical analysis}

The outcome was suicide reattempt, and the explanatory variables were the characteristics of the patient at entry and during followup in VigilanS, at the first inclusion in VigilanS if there were several. The recurrence was identified by a second entry in Vigilans. The list of variables and description can be found in Appendices 1 and 2.

We performed three types of analyses: descriptive analyses, bivariate analyses, and multivariate analyses. A survival analysis was also done.

\section{Descriptive analysis}

A general description was made on all the patients in order to give the size of each variable, as well as on the non-primary suicide attempters successfully contacted during the D10-D21 call.

\section{Survival analysis of suicide reattempt}

As suicide reattempt is a time-dependent event, censored on the right, it was treated by survival analysis, performed by the KaplanMeyer method. This made it possible to estimate (a) the median time of suicide reattempt after inclusion in Vigilans; and (b) the rate of patients having reiterated at a given time.

The survival analysis of suicide reattempt included all patients selected in our study. The duration of follow-up depends on the last successful telephone call with the patient (difference between the SA date and the date of the last successful telephone). The last successful call can be either the last successful call made to the patient or received from the patient. For those with no successful telephone calls, the duration of follow-up depends on the end date of our study (difference between the SA date and the end date of the study "1st July 2019"). The event analyzed is the suicide reattempt, the time of occurrence of which is obtained by the difference between the date of the first SA and the date of the first suicide reattempt.

Bivariate and multivariate analysis

The event to be studied being time-dependent, we performed Cox models. The duration of follow-up concerns the difference between date of SA and the end date of the study "July 1, 2019") for those who do not have the event; the difference between the date of the first SA and the date of the first suicidal reattempt for those who have the event.

Bivariate analysis was performed to study the relationship between two variables: dependent and independent. Variables whose $p$-value was less than 0.1 in bivariate analysis were selected for the multivariate analysis. For variables with multiple modalities, the global effect of the variable was also studied in order to include them in the multivariate analysis (global $p$-value less than 0.1 ). Analyses were adjusted for age and gender, which were considered as potentially confounding factors.

The multivariate analysis was performed using the multivariate Cox model. We used a step-by-step top-down selection. Before further interpreting the model and the significance of the effects, we tested the hypothesis of the model's validity by analyzing residuals over time (time-dependent co-variables). According to this hypothesis of validity, a cox model is valid if the residuals are not timedepending.
A $p$-value less than 0.05 was considered statistically significant, as well as a hazard ratio (HR) that did not include the value 1 in its 95\% confidence interval. The software used was $\mathrm{R}$, version 4.0.5.

\section{Results}

From January 1, 2015 to December 31, 2018, we had 10,666 patients, of which 905 patients $(7.6 \%)$ had a suicide reattempt (Figure 1).

\section{Patient description}

The mean age of all patients was $40.6 \pm 15$ years. Most patients were women $(58.7 \%)$ and from the North (54.5\%). The most frequent length of hospitalization was 1 day (48\%) and the majority of SA was by voluntary drug intoxication (VDI) (83.2\%) (Table 1).

Concerning primary and non-primary suicide attempters, there were some variations: there were more women among non-primary suicide attempters than among the primary suicide attempters $(61.4$ vs. $56.3 \%$ ), more alcoholics among non-primary suicide attempters than primary suicide attempters ( 54.6 vs. $48.5 \%$ ), but fewer patients with a companion in the emergency room among the non-primary suicide attempters as opposed to the primary suicide attempters (69.9 vs. $79.0 \%)$. Calls made and received were higher among the non-primary suicide attempters than among the primary suicide attempters (Table 1).

Among the non-primary suicide attempters interviewed on D10-D21 call (Table 1), more than three fourth of patients needed help (77.4\%) and more than half of the patients had postcards sent following this interview (62.8\%). Apart from VigilanS, most patients were followed by a psychiatrist $(65.8 \%)$.

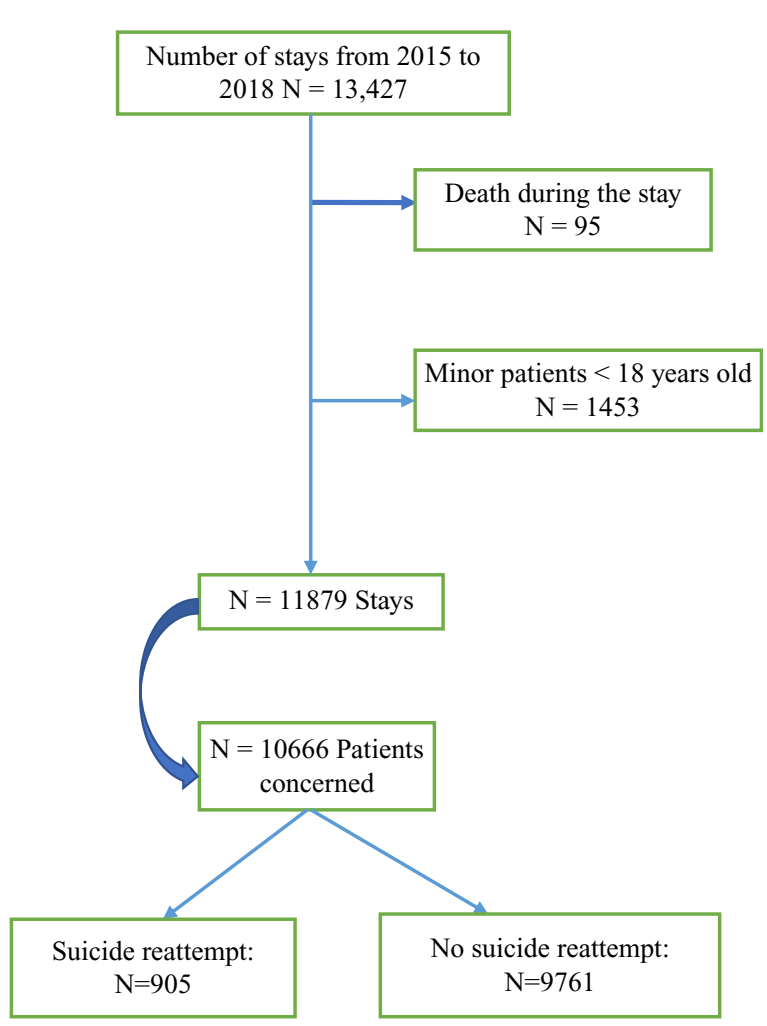

Figure 1. Flow chart for patient selection in the analysis. 
Table 1. Description of patients at first entry into Vigilans.

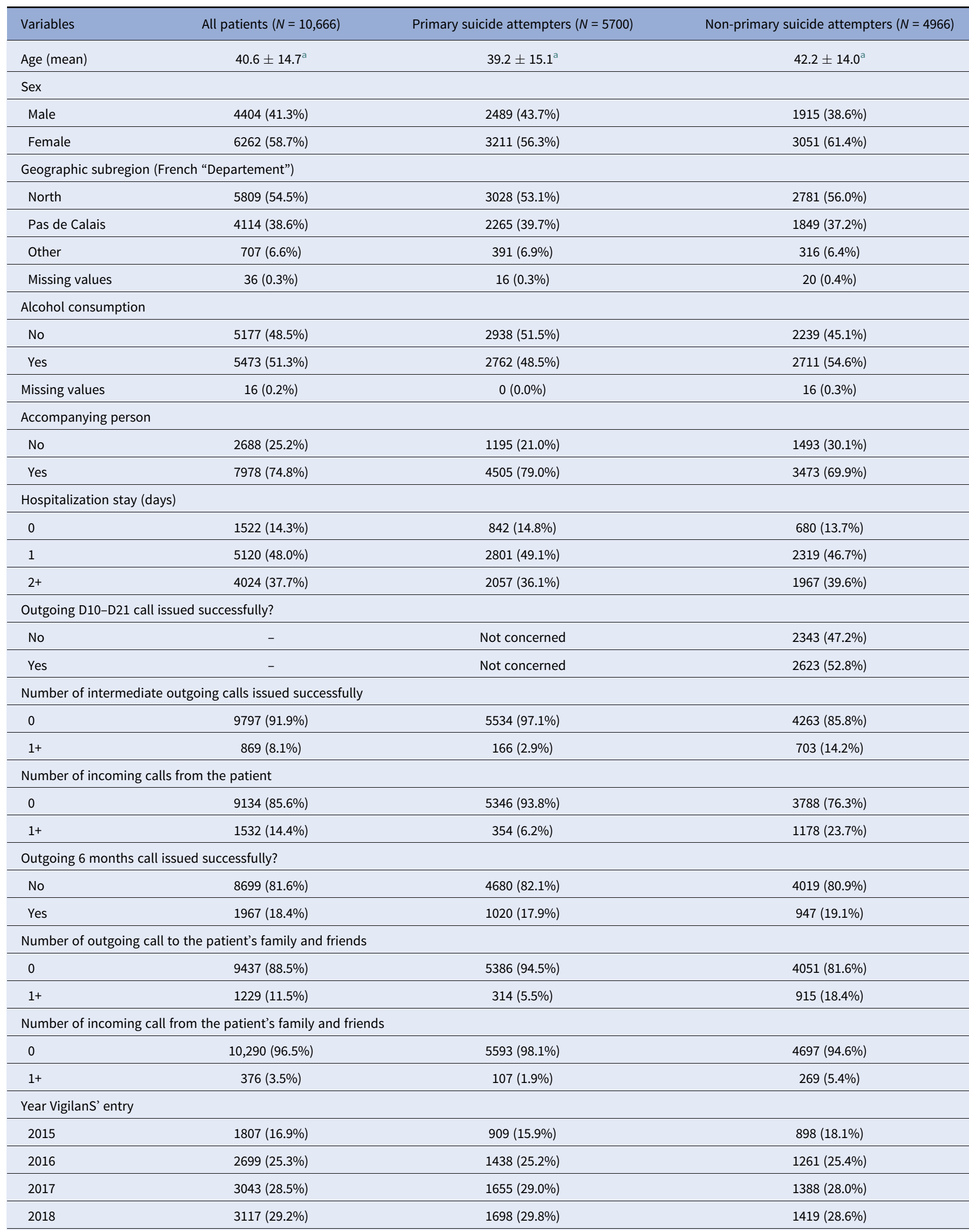


Table 1. Continued

\begin{tabular}{|c|c|c|c|}
\hline Variables & All patients $(N=10,666)$ & Primary suicide attempters $(N=5700)$ & Non-primary suicide attempters $(N=4966)$ \\
\hline \multicolumn{4}{|l|}{ Means of SA } \\
\hline \multicolumn{4}{|l|}{ VDI } \\
\hline No & $1791(16.8 \%)$ & $970(17.0 \%)$ & $821(16.5 \%)$ \\
\hline Yes & $8875(83.2 \%)$ & $4730(83.0 \%)$ & $4145(83.5 \%)$ \\
\hline \multicolumn{4}{|l|}{ Hanging } \\
\hline No & $10,122(94.9 \%)$ & $5349(93.8 \%)$ & $4773(96.1 \%)$ \\
\hline Yes & $544(5.1 \%)$ & $351(6.2 \%)$ & $193(3.9 \%)$ \\
\hline \multicolumn{4}{|l|}{ Phlebotomy } \\
\hline No & $9877(92.6 \%)$ & $5313(93.2 \%)$ & $4564(91.9 \%)$ \\
\hline Yes & $789(7.4 \%)$ & $387(6.8 \%)$ & $402(8.1 \%)$ \\
\hline \multicolumn{4}{|c|}{ Others (Firearms, Lesions, Drowning, Jump) } \\
\hline No & $10,327(96.8 \%)$ & $5515(96.8 \%)$ & $4812(96.9 \%)$ \\
\hline Yes & $339(3.2 \%)$ & $185(3.2 \%)$ & $154(3.1 \%)$ \\
\hline Variables of D10-D2 & es successfully & & $(N=2623)$ \\
\hline \multicolumn{4}{|c|}{ Evolution of discomfort since SA } \\
\hline Stationary & - & - & $805(30.7 \%)$ \\
\hline Favorable & - & - & $1720(65.6 \%)$ \\
\hline Unfavorable & - & - & $98(3.7 \%)$ \\
\hline \multicolumn{4}{|l|}{ Need help } \\
\hline No & - & - & $594(22.6 \%)$ \\
\hline Yes & - & - & $2029(77.4 \%)$ \\
\hline \multicolumn{4}{|c|}{ Followed by a psychiatrist outside Vigilans } \\
\hline No & - & - & $896(34.2 \%)$ \\
\hline Yes & - & - & $1728(65.8 \%)$ \\
\hline \multicolumn{4}{|c|}{ Patient's state at the end of the interview } \\
\hline Good & - & - & $1039(39.6 \%)$ \\
\hline Poor, not in crisis & - & - & $1488(56.7 \%)$ \\
\hline In crisis & - & - & $96(3.7 \%)$ \\
\hline
\end{tabular}

Abbreviation: SA, suicide attempt.

${ }^{\mathrm{a}}$ Means $\pm \mathrm{SD}$.

\section{Suicide reattempt survival curve}

The rate of suicide reattempt in our study was $8 \%$. Figure 2 shows the survival analysis of suicide reattempt in all suicide attempters as a function of their length of follow-up in months. We see that nearly $26 \%$ of patients had a suicide reattempt during the first 6 months of follow-up, nearly $42 \%$ within 12 months. The mean time of suicide reattempt was 18 months.

\section{Bivariate analysis}

After adjusting for age and sex (Table 2), there was a significant relationship between suicide reattempt and: being a non-primary suicide attempter; regular alcohol use; being unaccompanied during the emergency room visit; no calls made to or received from the patient; no calls made to or receive from entourage; year of entry in VigilanS; means of suicide by VDI, hanging, and phlebotomy.

The variables significantly associated with suicide reattempt in primary suicide attempters were alcohol users; length of hospitalization; no calls received from the patient; means of SA by hanging (Table 3).

In contrast, among non-primary suicide attempters, the variables significantly associated with suicide reattempt were: no presence of a companion during the visit to the emergency room; no calls made to and received from the patient; year of entry in VigilanS; means of SA by VDI and hanging (Table 3). Variables concerning the call at D10-D21 were not significant.

\section{Multivariate analysis}

After analyzing the validity of the model, the variable "years of entry into Vigilans" was not taken into account in the final model, because their residuals had a very strong relationship with time, making Cox's model less valid. According to the model validity assumption, the residuals should not be time dependent. The year effect increases linearly with time. The other effects appear to be fixed (See "Appendices 3 and 4"). 


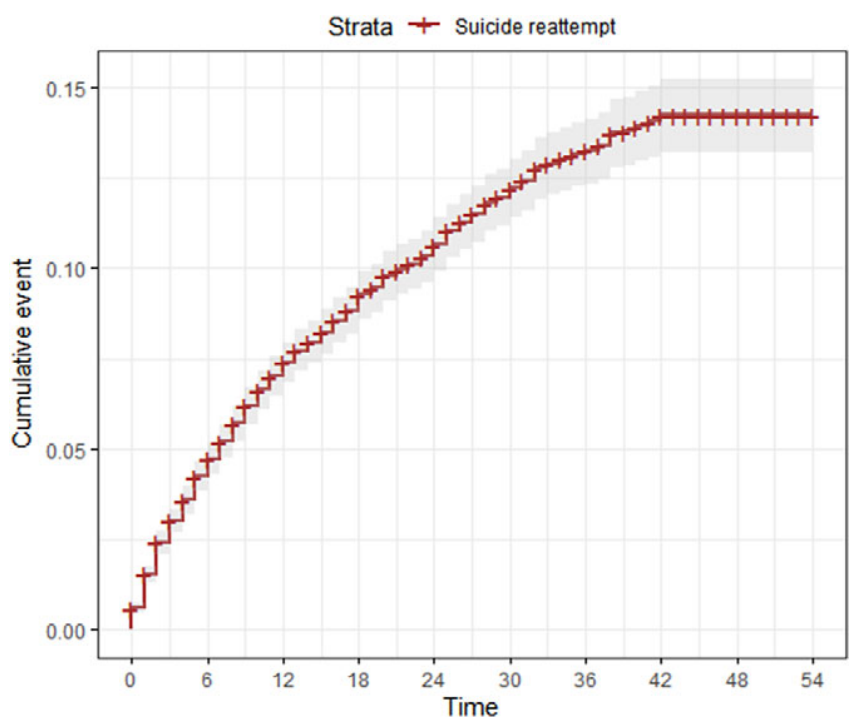

Figure 2. Suicide reattempt survival analysis as a function of follow-up time in months $(N=10,666)$.
In our multivariate analysis (Table 4), the patients at risk of suicide reattempt were non-primary suicide attempters $(\mathrm{HR}=4.85)$; patients whose call was not made to their family and friends $(\mathrm{HR}=1.23)$, and patients who attempted suicide by VDI $(H R=1.32)$ and phlebotomy $(H R=1.34)$. Alcohol consumption was identified as a risk factor for suicide reattempt in primary suicide attempters $(\mathrm{HR}=1.26)$ and patients without a companion during the emergency room visit as a risk factor for suicide reattempt in non-primary suicide attempters $(\mathrm{HR}=1.38)$.

However, the protective factors identified were hanging ( $\mathrm{HR}=0.49, p=0.008)$ and patients who did not make calls to VigilanS during follow-up $(\mathrm{HR}=0.61, p<0.001)$.

\section{Discussion}

Main findings and comparison with findings from other studies

Suicide reattempt is one of the important concerns in suicide prevention, as repetition can lead to final suicide. It is important to know which types of patients are at risk of suicide recurrence, especially when they have been followed by a post-attempted

Table 2. Comparison of general characteristics of suicide reattempt and no suicide reattempt patients and simple age and sex-adjusted logistic regression.

\begin{tabular}{|c|c|c|c|c|c|c|}
\hline Variables & \multicolumn{5}{|c|}{ All patients } & $\mathrm{p}$ \\
\hline Age (mean) & $41.0 \pm 13.1^{\mathrm{a}}$ & $40.5 \pm 14.8^{\mathrm{a}}$ & & & & \\
\hline \multicolumn{7}{|l|}{ Sex } \\
\hline Male & $342(37.8 \%)$ & $4062(41.6 \%)$ & & & & \\
\hline North & $508(56.1 \%)$ & $5301(54.3 \%)$ & 1.10 & $0.840-1.453$ & 0.475 & \\
\hline Pas de Calais & $337(37.2 \%)$ & $3777(38.7 \%)$ & 1.04 & $0.788-1.381$ & 0.768 & \\
\hline Others $^{b}$ & $57(6.3 \%)$ & $650(6.7 \%)$ & & & & \\
\hline \multicolumn{7}{|l|}{ Suicide attempters } \\
\hline $\mathrm{No}^{\mathrm{b}}$ & $400(44.2 \%)$ & $4777(48.9 \%)$ & & & & \\
\hline Yes & $500(54.2 \%)$ & $4973(51.0 \%)$ & 1.24 & $1.083-1.414$ & 0.002 & \\
\hline \multicolumn{7}{|l|}{ Accompanying person } \\
\hline No & $290(32.0 \%)$ & $2398(24.6 \%)$ & 1.45 & $1.262-1.671$ & $<0.001$ & \\
\hline Yes $^{\mathrm{b}}$ & $615(68.0 \%)$ & $7363(75.4 \%)$ & & & & \\
\hline \multicolumn{7}{|l|}{ Hospitalization stay (days) } \\
\hline $0^{b}$ & $123(13.6 \%)$ & $1399(14.3 \%)$ & & & & \\
\hline 1 & $413(45.6 \%)$ & $4707(48.2 \%)$ & 0.96 & $0.787-1.178$ & 0.713 & $0.02^{c}$ \\
\hline
\end{tabular}


Table 2. Continued

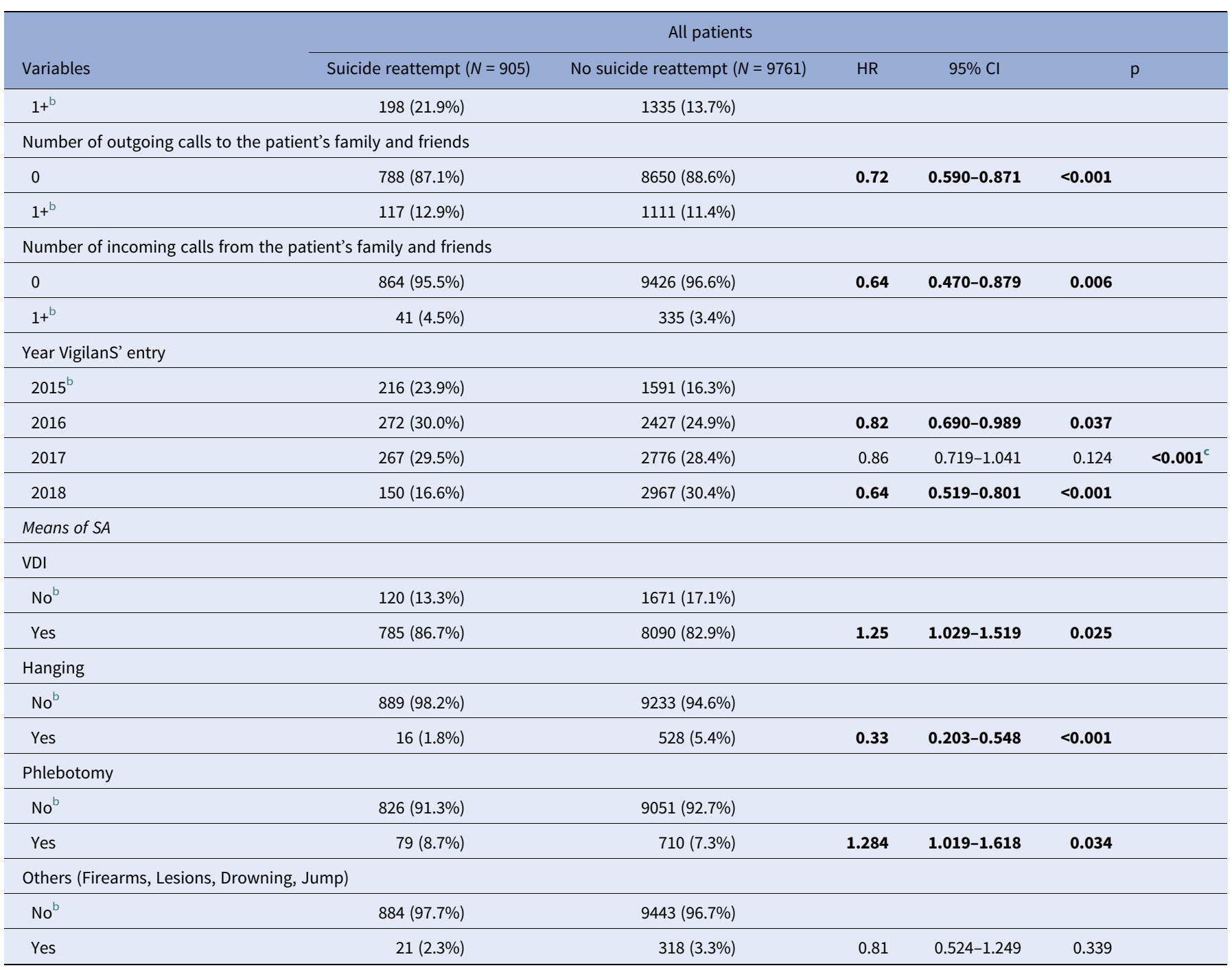

Abbreviations: $\mathrm{Cl}$, confidence interval; $\mathrm{HR}$, hazard ratio; SA, suicide attempt; VDI, voluntary drug intoxication.

${ }^{\mathrm{a}}$ Means $\pm \mathrm{SD}$.

${ }^{\mathrm{b}}$ Reference modality in the variable.

${ }^{\mathrm{C}} \mathrm{Global} p$-value of the multimodality variable.

Bold values: significant relationship with suicide reattempt

prevention program. In our study, the program is installed in hospitals in the Nord-Pas-de-Calais region. The interest and the originality of this study was to focus on a large population observed in real conditions.

The rate of suicide reattempt in our study was $8 \%$, and the mean time of suicide reattempt according to our survival results was 18 months. This rate of suicide reattempt was lower to rates obtained in other studies. According to the study by Exbrayat et al. also concerning an BCI, the rate of reattempt among study patients was 12.6 and $21.2 \%$ in the study by Carter et al. [36,37]. Lilley et al. also found $17 \%$, although survival analysis revealed a suicide reattempt rate of $33 \%$ of patients in the year following an episode [14], lower than our result, $42 \%$ in 1 year. In other studies, suicide reattempt occurred slightly earlier, within 3-6 months after SA [9,38-40]. According to the study by Carter et al., more than half of the reattempt occur nearly 6 months after the intervention [37]. This thus suggests the effectiveness of VigilanS on suicide reattempt, from the first entry into VigilanS. Maintaining contact is of great importance for the patient's future.
Non-primary suicide attempters were four times more likely to repeat suicide than the primary suicide attempters. This result is similar to several studies, which have also shown that a history of $\mathrm{SA}$ is a risk factor for suicide reattempt [41-44]. In the study by Ribeiro et al., non-primary suicide attempters were 3.6 times more likely to repeat suicide [44], and the higher the number of previous SA, the higher the risk [43]. This risk of suicide reattempt identified in our study in non-primary suicide attempters supports the hypothesis that patients who have already made a failed SA have a high suicidal intention, and may have acquired the ability to engage in suicidal behavior with increased tolerance to physical pain and decreased fear of death, which may lead to a fatal suicide act $[45,46]$. It is in this context that VigilanS has set up a specific telephone call to patient non-primary suicide attempters, between the 10th day and 21 st day after their SA, because these patients are at high risk of suicide reattempt.

We found that the means used during SA were associated with suicide reattempt; patients who attempted suicide by VDI and Phlebotomy were more likely to have a suicide reattempt than those 
Table 3. Comparison of general characteristics of suicide reattempt and no suicide reattempt patients and simple age and sex-adjusted logistic regression.

\begin{tabular}{|c|c|c|c|c|c|c|c|c|c|c|c|c|}
\hline \multirow[b]{2}{*}{ Variables } & \multicolumn{6}{|c|}{ Primary suicide attempters } & \multicolumn{6}{|c|}{ Non-primary suicide attempters } \\
\hline & $\begin{array}{l}\text { Suicide } \\
\text { reattempt } \\
(N=271)\end{array}$ & $\begin{array}{l}\text { No suicide } \\
\text { reattempt } \\
(N=5429)\end{array}$ & $\mathrm{HR}$ & $95 \% \mathrm{Cl}$ & $p$ & 0 & $\begin{array}{l}\text { Suicide } \\
\text { reattempt } \\
(N=634)\end{array}$ & $\begin{array}{l}\text { No suicide } \\
\text { reattempt } \\
(N=4332)\end{array}$ & HR & $95 \% \mathrm{Cl}$ & & $p$ \\
\hline Age & $40.0 \pm 13.7$ & $39.1 \pm 15.2$ & & & & & $41.5 \pm 12.9$ & $42.2 \pm 14.2$ & & & & \\
\hline \multicolumn{13}{|l|}{ Sex } \\
\hline Male & $116(42.8 \%)$ & $2373(43.7 \%)$ & & & & & $226(35.7 \%)$ & $1689(39.0 \%)$ & & & & \\
\hline Female & $155(57.2 \%)$ & $3056(56.3 \%)$ & & & & & $408(64.3 \%)$ & $2643(61.0 \%)$ & & & & \\
\hline \multicolumn{13}{|c|}{ Geographic subregion (French "Departement") } \\
\hline North & $134(49.4 \%)$ & $2894(53.3 \%)$ & 0.96 & $0.589-1.575$ & 0.881 & & $374(59.0 \%)$ & $2407(55.6 \%)$ & 1.07 & $0.796-1.487$ & 0.692 & \\
\hline Pas de Calais & $118(43.6 \%)$ & $2147(39.5 \%)$ & 1.16 & $0.708-1.909$ & 0.551 & & $219(34.6 \%)$ & $1630(37.6 \%)$ & 0.96 & $0.686-1.356$ & 0.835 & \\
\hline Others ${ }^{a}$ & $18(6.6 \%)$ & $373(6.9 \%)$ & & & & & $39(6.1 \%)$ & $277(6.4 \%)$ & & & & \\
\hline \multicolumn{13}{|c|}{ Alcohol consumption } \\
\hline $\mathrm{No}^{\mathrm{a}}$ & $119(43.9 \%)$ & $2819(51.9 \%)$ & & & & & $281(44.3 \%)$ & 1958 (45.2\%) & & & & \\
\hline Yes & $152(56.1 \%)$ & $2610(48.1 \%)$ & 1.36 & $1.066-1.737$ & 0.013 & & $348(54.9 \%)$ & $2363(54.6 \%)$ & 1.01 & $0.858-1.180$ & 0.939 & \\
\hline \multicolumn{13}{|c|}{ Accompanying person } \\
\hline No & $62(22.9 \%)$ & $1133(20.9 \%)$ & & & & & $228(36.0 \%)$ & $1265(29.2 \%)$ & & & & \\
\hline Yes $^{\mathrm{a}}$ & $209(77.1 \%)$ & $4296(79.1 \%)$ & 1.10 & $0.828-1.463$ & 0.508 & & $406(64.0 \%)$ & $3067(70.8 \%)$ & 1.18 & $1.003-1.390$ & 0.047 & \\
\hline \multicolumn{13}{|c|}{ Hospitalization stay (days) } \\
\hline $0^{\mathrm{a}}$ & $45(16.6 \%)$ & $797(14.7 \%)$ & & & & & $78(12.3 \%)$ & $602(13.9 \%)$ & & & & \\
\hline 1 & $110(40.6 \%)$ & $2691(49.6 \%)$ & 0.71 & $0.502-1.006$ & 0.0538 & \multirow[t]{2}{*}{$0.008^{b}$} & $303(47.8 \%)$ & $2016(46.5 \%)$ & 1.12 & $0.876-1.442$ & 0.357 & \multirow[t]{2}{*}{$0.232^{b}$} \\
\hline $2+$ & $116(42.8 \%)$ & $1941(35.7 \%)$ & 1.06 & $0.746-1.494$ & 0.759 & & $253(39.9 \%)$ & $1714(39.6 \%)$ & 1.23 & $0.956-1.592$ & 0.107 & \\
\hline \multicolumn{13}{|c|}{ Number of outgoing call issued successfully } \\
\hline 0 & $257(94.8 \%)$ & $5202(95.8 \%)$ & 0.82 & $0.386-1.742$ & 0.606 & & $476(75.1 \%)$ & $3399(78.5 \%)$ & 0.69 & $0.561-0.856$ & $<0.001$ & \\
\hline $1++^{\text {a }}$ & $14(5.2 \%)$ & $227(4.2 \%)$ & & & & & $158(24.9 \%)$ & $933(21.5 \%)$ & & & & \\
\hline \multicolumn{13}{|c|}{ Number of incoming calls from the patient } \\
\hline 0 & $247(91.1 \%)$ & $5099(93.9 \%)$ & 0.45 & $0.291-0.683$ & $<0.001$ & & $460(72.6 \%)$ & $3327(76.8 \%)$ & 0.62 & $0.521-0.747$ & $<0.001$ & \\
\hline $1+^{a}$ & $24(8.9 \%)$ & $330(6.1 \%)$ & & & & & $174(27.4 \%)$ & $1005(23.2 \%)$ & & & & \\
\hline \multicolumn{13}{|c|}{ Number of outgoing calls to the patient's family and friends } \\
\hline 0 & 264 (97.4\%) & $5122(94.3 \%)$ & 2.12 & $1.001-4.491$ & 0.05 & & $524(82.6 \%)$ & $3528(81.4 \%)$ & 1.12 & $0.910-1.375$ & 0.286 & \\
\hline
\end{tabular}


Table 3. Continued

\begin{tabular}{|c|c|c|c|c|c|c|c|c|c|c|c|c|}
\hline \multirow[b]{2}{*}{ Variables } & \multicolumn{6}{|c|}{ Primary suicide attempters } & \multicolumn{6}{|c|}{ Non-primary suicide attempters } \\
\hline & $\begin{array}{l}\text { Suicide } \\
\text { reattempt } \\
(N=271)\end{array}$ & $\begin{array}{l}\text { No suicide } \\
\text { reattempt } \\
(N=5429)\end{array}$ & $\mathrm{HR}$ & $95 \% \mathrm{Cl}$ & $p$ & & $\begin{array}{l}\text { Suicide } \\
\text { reattempt } \\
(N=634)\end{array}$ & $\begin{array}{l}\text { No suicide } \\
\text { reattempt } \\
(N=4332)\end{array}$ & HR & $95 \% \mathrm{Cl}$ & & $p$ \\
\hline $1+^{\mathrm{a}}$ & $7(2.6 \%)$ & $307(5.7 \%)$ & & & & & $110(17.3 \%)$ & $804(18.6 \%)$ & & & & \\
\hline \multicolumn{13}{|c|}{ Number of incoming calls from the patient's family and friends } \\
\hline 0 & $268(98.9 \%)$ & $5325(98.1 \%)$ & 1.67 & $0.535-5.221$ & 0.377 & & $596(94.0 \%)$ & $4101(94.7 \%)$ & 0.90 & $0.649-1.252$ & 0.536 & \\
\hline $1+^{a}$ & $3(1.1 \%)$ & $104(1.9 \%)$ & & & & & $38(6.0 \%)$ & 231 (5.3\%) & & & & \\
\hline \multicolumn{13}{|c|}{ Year VigilanS' entry } \\
\hline $2015^{\mathrm{a}}$ & $50(18.4 \%)$ & $859(15.8 \%)$ & & & & & $166(26.2 \%)$ & $732(16.9 \%)$ & & & & \\
\hline 2016 & $78(28.8 \%)$ & $1360(25.0 \%)$ & 1.08 & $0.756-1.546$ & 0.669 & & $194(30.6 \%)$ & $1067(24.6 \%)$ & 0.67 & $0.541-0.822$ & $<0.001$ & \\
\hline 2017 & 88 (32.5\%) & $1567(28.9 \%)$ & 1.28 & $0.894-1.833$ & 0.178 & $0.529^{b}$ & $179(28.2 \%)$ & $1209(27.9 \%)$ & 0.70 & $0.565-0.871$ & 0.001 & $<0.001^{b}$ \\
\hline 2018 & 55 (20.3\%) & $1643(30.3 \%)$ & 1.08 & $0.724-1.619$ & 0.700 & & 95 (15.0\%) & $1324(30.6 \%)$ & 0.47 & $0.364-0.614$ & $<0.001$ & \\
\hline \multicolumn{13}{|l|}{ Means of SA } \\
\hline \multicolumn{13}{|l|}{ VDI } \\
\hline $\mathrm{No}^{\mathrm{a}}$ & 38 (14.0\%) & $932(17.2 \%)$ & & & & & $82(12.9 \%)$ & $739(17.1 \%)$ & & & & \\
\hline Yes & $233(86.0 \%)$ & $4497(82.8 \%)$ & 1.21 & $0.854-1.720$ & 0.281 & & $552(87.1 \%)$ & $3593(82.9 \%)$ & 1.35 & $1.067-1.702$ & 0.012 & \\
\hline \multicolumn{13}{|l|}{ Hanging } \\
\hline $\mathrm{No}^{\mathrm{a}}$ & $264(97.4 \%)$ & 5085 (93.7\%) & & & & & $625(98.6 \%)$ & $4148(95.7 \%)$ & & & & \\
\hline Yes & $7(2.6 \%)$ & $344(6.4 \%)$ & 0.40 & $0.188-0.853$ & 0.018 & & $9(1.4 \%)$ & $184(4.3 \%)$ & 0.40 & $0.206-0.771$ & 0.006 & \\
\hline \multicolumn{13}{|l|}{ Phlebotomy } \\
\hline $\mathrm{No}^{\mathrm{a}}$ & 248 (91.5\%) & 5065 (93.3\%) & & & & & $578(91.2 \%)$ & 3986 (92.0\%) & & & & \\
\hline Yes & $23(8.5 \%)$ & $364(6.7 \%)$ & 1.32 & $0.861-2.029$ & 0.203 & & $56(8.8 \%)$ & $346(8.0 \%)$ & 1.09 & $0.826-1.431$ & 0.551 & \\
\hline \multicolumn{13}{|c|}{ Others (Firearms, Lesions, Drowning, Jump) } \\
\hline $\mathrm{No}^{\mathrm{a}}$ & $265(97.8 \%)$ & $5250(96.7 \%)$ & & & & & $619(97.6 \%)$ & $4193(96.8 \%)$ & & & & \\
\hline Yes & $6(2.2 \%)$ & $179(3.3 \%)$ & 0.73 & $0.326-1.655$ & 0.457 & & $15(2.4 \%)$ & $139(3.2 \%)$ & 0.81 & $0.487-1.360$ & 0.433 & \\
\hline \multicolumn{13}{|c|}{ Variables of D10-D21 calls issues successfully $($ Reattempt $=321)($ No reattempt $=2302)$} \\
\hline \multicolumn{13}{|c|}{ Evolution of discomfort since SA } \\
\hline Favorable $^{\mathrm{a}}$ & - & - & - & - & & - & $199(62.0 \%)$ & $1521(66.1 \%)$ & & & & \\
\hline Stationary & - & - & - & - & & - & $106(33.0 \%)$ & $699(30.4 \%)$ & 0.92 & $0.723-1.163$ & 0.473 & $0.559^{b}$ \\
\hline Unfavorable & - & - & - & - & & - & $16(5.0 \%)$ & $82(3.5 \%)$ & 1.20 & $0.720-1.999$ & 0.485 & \\
\hline Need help & & & & & & & & & & & & \\
\hline
\end{tabular}




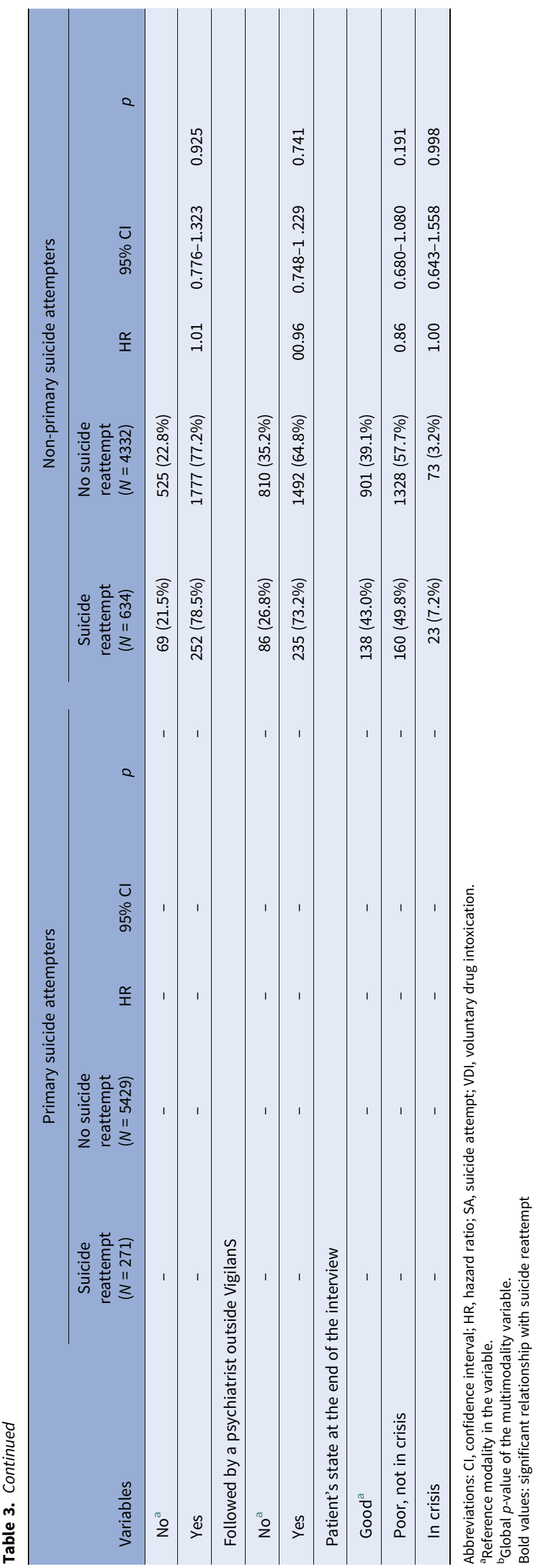

who used another method. However, those who attempted suicide by hanging, were less likely to have a suicide reattempt. This result is almost similar to that of Perry et al., who found that rates of recurrence were low in patients who used methods such as hanging, but also chemical poisoning, which is rather identified as a risk factor in our study [15]. According to Oflson et al., the risk of suicide reattempt did not differ significantly between patients who initially used violent (firearm-related methods and "other violent" methods) and nonviolent methods (poisoning or cutting) [47]. These differences can be explained by the fact that these studies were carried out on a national level, unlike our study which was carried out on a regional level and the methods of attempted suicides may differ from one region to another.

Patients who had not made calls to VigilanS were identified as being at lower risk of suicide reattempt. Incoming intermediate calls (calls made outside D10-D21 call and 6-month call) are usually long calls from patients in need of help and/or listening, and outgoing intermediaries' calls are often intended for patients at high risk of suicide, or for patients who have could not be reached in previous telephone calls. Regardless of the type of incoming or outgoing call, there is a risk of repeat suicide attempt in these patients, which necessitates the importance of paying special attention to these patients through telephone follow-ups. However, it was found that no call to the relatives was a risk factor for a new suicide attempt. This result shows the importance of family and friends in supporting suicidal patients, helping the patient to avoid making a new suicide attempt.

Other risk factors such as alcohol consumption and absence of a companion during his or her visit in the emergency room were specifically identified in primary suicide attempters and nonprimary suicide attempters. Alcohol consumption is an important profile of SA. Nearly a quarter of suicide deaths are directly attributable to alcohol [48], which is often used in SA (both nonlethal and lethal) [49-51]. Regarding the absence of a companion during his or her visit in the emergency room. The presence of a person around the patient, especially one with whom the patient shares many affinities, leads to less loneliness. Liu et al. also emphasize the importance of a relative. According to them, hopelessness and social support emerged as significant predictors of suicide reattempt [52]. By Holma et al., a presence of partner is an important factor in protecting patients against from SA, in support [53].

\section{Strengths and weaknesses}

However, our study had some limitations. It was based only on a limited number of patients, due to a large number of patients lost to follow-up (LFU) in VigilanS. More than half of the patients were LFU (no news from them during the program after several contact attempts). In addition, patients who died during the first follow-up were excluded from our study, which may have been due to a new suicide attempt or illness or other reason (95 patients). This may modify our estimate of the suicide reattempt rate. However, if there is a recurrence, then the patient re-enters VigilanS (unless the patient dies, is not hospitalized, or does his SA outside the NPC region, which is a minority). The recurrence is therefore correctly identified for a majority of patients.

For the survival analysis, the last successful telephone call was considered as the end date of the follow-up, and the end date of the study for those with no successful telephone calls. This variation of the date of the follow-up could influence the estimate of the mean duration of suicide reattempt. 
Table 4. Multiple regression of suicide reattempt and no suicide reattempt patients.

\begin{tabular}{|c|c|c|c|c|c|c|c|c|c|}
\hline \multirow[b]{2}{*}{ Variables } & \multicolumn{3}{|c|}{ All patients } & \multicolumn{3}{|c|}{ Primary suicide attempters } & \multicolumn{3}{|c|}{ Non-primary suicide attempters } \\
\hline & HR & $95 \% \mathrm{Cl}$ & $p$ & HR & $95 \% \mathrm{Cl}$ & $\mathrm{p}$ & HR & $95 \% \mathrm{Cl}$ & $\mathrm{p}$ \\
\hline Suicide attempters "Non-Primary suicide attempters" & 4.85 & 4.171-5.646 & $<0.001$ & - & - & - & - & - & - \\
\hline Alcohol consumption "Yes" & 1.11 & $0.973-1.269$ & $>0.1$ & 1.26 & $1.102-1.440$ & $<0.001$ & - & - & - \\
\hline Accompanying "No" & 1.14 & $0.991-1.319$ & 0.066 & - & - & - & 1.38 & $1.203-1.592$ & $<0.001$ \\
\hline \multicolumn{10}{|l|}{ Hospitalization stay } \\
\hline "1 day" & 0.92 & $0.749-1.124$ & $>0.1$ & 0.92 & $0.754-1.129$ & $>0.1$ & - & - & - \\
\hline "2 days" & 1.13 & $0.918-1.388$ & $>0.1$ & 1.14 & $0.932-1.404$ & $>0.1$ & - & - & - \\
\hline $\begin{array}{l}\text { Number of outgoing intermediate call issued } \\
\text { successfully "0 call" }\end{array}$ & - & - & - & - & - & - & 0.78 & $0.611-0.999$ & 0.049 \\
\hline Number of incoming intermediates calls " 0 call" & 0.61 & $0.518-0.723$ & $<0.001$ & 0.36 & $0.307-0.425$ & $<0.001$ & 0.40 & $0.327-0.487$ & $<0.001$ \\
\hline $\begin{array}{l}\text { Number of outgoing calls to the patient's family and } \\
\text { friends " } 0 \text { call" }\end{array}$ & 1.23 & $1.013-1.682$ & 0.037 & - & - & - & - & - & - \\
\hline VDI “Yes" & 1.32 & $1.036-1.682$ & 0.025 & - & - & - & - & - & - \\
\hline Hanging "Yes" & 0.49 & $0.288-0.828$ & 0.008 & 0.34 & $0.205-0.555$ & $<0.001$ & 0.36 & $0.218-0.590$ & $<0.001$ \\
\hline Phlebotomy "Yes" & 1.34 & $1.013-1.770$ & 0.040 & - & - & - & - & - & - \\
\hline
\end{tabular}

Abbreviations: $\mathrm{Cl}$, confidence interval; $\mathrm{HR}$, hazard ratio; $\mathrm{VDI}$, voluntary drug intoxication.

Bold values: significant relationship with suicide reattempt

Another limitation is that our population was based only on the hospital environment, and some of the SA in the population do not lead to hospitalization. In France, however, the proportion of nonhospitalized SA is small, around 8\% [54], but this can still pose a difficulty in generalizing our results to the entire population.

In addition, not all patients admitted to the emergency department during our study period were fully analyzed. Not all patients admitted to the Emergency Department included in VigilanS, and some patients who were not in the study may have different suicidal behaviors from those included in the study. This nonexhaustive inclusion may therefore influence our analyses, mainly the rate of suicide reattempt.

Analysis on the patient's psychiatric profile would have been desirable but could not be carried out, as attempts to establish this profile proved too cumbersome in the context of a large-scale implanted program and were abandoned. It is still important to pay attention to other factors.

On the other hand, a strength of this study is the almost exhaustive collection over 4 years of data on patients passing through the care system following a SA, over an entire region. This study provides a baseline that can help in the design of suicide prevention interventions because, to our knowledge, no previous data on suicide reattempt among patients followed by a post-attempt system in France is available to allow comparisons. Our results provide knowledge on suicide reattempt, identify people at risk of suicide reattempt and allow for better post-suicide follow-up. In addition, the study evaluates the effectiveness VigilanS, which is based on a simple methodology that could easily be applied in other countries.

To conclude, after a SA, the risk suicide reattempt is present in some patients, especially non-primary suicide attempters with a very high risk of suicide reattempt. However, VigilanS plays an important role in post-attempt follow-up, with a low rate of suicide reattempt compared to the literature. VigilanS suggests the possibility of better identification of patients likely to repeat, and to strengthen prevention efforts in these populations.

Acknowledgment. The authors gratefully acknowledge the contribution of all investigators who contributed to our study.

Financial support. Larissa D. Fossi was supported by a fellowship from the Faculty of Medicine of Paris-Sud University.

Conflict of interest. The authors declare that they have no competing interests.

Authorship contributions. All authors made significant contributions to this study and read and approved the final manuscript. Antoine Messiah and Guillaume Vaiva contributed to the conception, analysis, and critical revisions. Larissa D. Fossi contributed to the analysis, drafting of the manuscript, interpretation, and critical revisions. Christophe Debien and Anne-Laure Demarty contributed to the interpretation and critical revisions.

Data availability statement. The data that support the findings of this study are available from Larissa D. Fossi, with the permission of Guillaume Vaiva.

Ethical statement. The VigilanS study was authorized by the French Ministry of Health and approved by the Comité de Protection des Personnes of NordPas-de-Calais region (Ethics Committee). It was registered with ClinicalTrials. gov (NCT03134885).

$\begin{array}{ll}\text { Abbreviations } & \\ \text { BCI } & \begin{array}{l}\text { brief contact interventions } \\ \text { confidence interval }\end{array} \\ \text { CI } & \text { call between the 10th and 21st days after SA } \\ \text { D10-D21 } & \text { hazard ratio } \\ \text { HR } & \text { lost to follow-up } \\ \text { LFU } & p \text {-value } \\ p & \text { suicide attempt } \\ \text { SA } & \text { statistical units of analysis } \\ \text { SUA } & \text { voluntary drug intoxication } \\ \text { VDI } & \text { World Health Organization }\end{array}$




\section{References}

[1] World Health Organization (WHO). Suicide in the world: global health estimates, https://www.who.int/publications/i/item/suicide-in-the-world; 2019 [accessed 15 October 2020].

[2] Shepard DS, Gurewich D, Lwin AK, Reed GA Jr, Silverman MM. Suicide and suicidal attempts in the United States: costs and policy implications. Suicide Life Threat Behav. 2016;46:352-62.

[3] Vinet M-A, Le Jeanic A, Lefèvre T, Quelen C, Chevreul K. Le fardeau économique du suicide et des tentatives de suicide en France. Rev Epidemiol Sante Publique. 2014;62:S62-3.

[4] World Health Organization (WHO). Preventing suicide: a global imperative. Geneva, Switzerland: World Health Organization; 2014.

[5] Wasserman D, Rihmer Z, Rujescu D, Sarchiapone M, Sokolowski M, Titelman D, et al. The European Psychiatric Association (EPA) guidance on suicide treatment and prevention. Eur Psychiatry. 2012;27:129-41.

[6] Weiner J, Richmond TS, Conigliaro J, Wiebe DJ. Military veteran mortality following a survived suicide attempt. BMC Public Health. 2011;11:374.

[7] Bostwick JM, Pabbati C, Geske JR, McKean AJ. Suicide attempt as a risk factor for completed suicide: even more lethal than we knew. Am J Psychiatr. 2016;173:1094-100.

[8] Haw C, Bergen H, Casey D, Hawton K. Repetition of deliberate self-harm: a study of the characteristics and subsequent deaths in patients presenting to a general hospital according to extent of repetition. Suicide Life Threat Behav. 2007;37:379-96.

[9] Arensman E, Griffin E, Corcoran P. Self-harm: extent of the problem and prediction of repetition. In: O'Connor RC, Pirkis J, editors. The international handbook of suicide prevention. Chichester, UK: John Wiley \& Sons, Ltd.; 2016, p. 61-73.

[10] Kapur N, Cooper J, King-Hele S, Webb R, Lawlor M, Rodway C, et al. The repetition of suicidal behavior: a multicenter cohort study. J Clin Psychiatry. 2006;67:1599-609.

[11] Elnour AA, Harrison J. Lethality of suicide methods. Inj Prev. 2008;14: $39-45$.

[12] Runeson B, Tidemalm D, Dahlin M, Lichtenstein P, Långström N. Method of attempted suicide as predictor of subsequent successful suicide: national long term cohort study. BMJ. 2010;341:c3222-2.

[13] Madge N, Hewitt A, Hawton K, de Wilde EJ, Corcoran P, Fekete S, et al. Deliberate self-harm within an international community sample of young people: comparative findings from the Child \& Adolescent Self-harm in Europe (CASE) study. J Child Psychol \& Psychiat. 2008;49:667-77.

[14] Lilley R, Owens D, Horrocks J, House A, Noble R, Bergen H, et al. Hospital care and repetition following self-harm: multicentre comparison of selfpoisoning and self-injury. Br J Psychiatry. 2008;192:440-5.

[15] Perry IJ, Corcoran P, Fitzgerald AP, Keeley HS, Reulbach U, Arensman E. The incidence and repetition of hospital-treated deliberate self harm: findings from the world's first national registry. PLoS One. 2012;7:e31663.

[16] Huang Y-C, Wu Y-W, Chen C-K, Wang LJ. Methods of suicide predict the risks and method-switching of subsequent suicide attempts: a community cohort study in Taiwan. Neuropsychiatr Dis Treat. 2014;10:711-8.

[17] World Health Organization (WHO). Prévention du suicide: l'état d'urgence mondial. Geneva, Switzerland: World Health Organization; 2014.

[18] Observatoire National du Suicide (ONS). Suicide: Enjeux éthiques de la prévention, singularités du suicide à l'adolescence. Paris, France: Santé Publique France; 2018.

[19] Milner AJ, Carter G, Pirkis J, Robinson J, Spittal MJ. Letters, green cards, telephone calls and postcards: systematic and meta-analytic review of brief contact interventions for reducing self-harm, suicide attempts and suicide. Br J Psychiatry. 2015;206:184-90.

[20] Inagaki M, Kawashima Y, Kawanishi C, Yonemoto N, Sugimoto T, Furuno $\mathrm{T}$, et al. Interventions to prevent repeat suicidal behavior in patients admitted to an emergency department for a suicide attempt: a metaanalysis. J Affect Disord. 2015;175:66-78.

[21] Vaiva G, Vaiva G, Ducrocq F, Meyer P, Mathieu D, Philippe A, et al. Effect of telephone contact on further suicide attempts in patients discharged from an emergency department: randomised controlled study. BMJ. 2006; $332: 1241-5$.
[22] Evans J, Evans M, Morgan HG, Hayward A, Gunnell D. Crisis card following self-harm: 12-month follow-up of a randomised controlled trial. Br J Psychiatry. 2005; 187:186-7.

[23] Motto JA, Bostrom AG. A randomized controlled trial of postcrisis suicide prevention. Psychiatr Serv. 2001;52:828-33.

[24] Carter GL, Clover K, Whyte IM, Dawson AH, D'Este C. Postcards from the EDge project: randomised controlled trial of an intervention using postcards to reduce repetition of hospital treated deliberate self poisoning. BMJ. 2005;331:805.

[25] Berrouiguet S, Alavi Z, Vaiva G, Courtet P, Baca-García E, Vidailhet P, et al. SIAM (suicide intervention assisted by messages): the development of a post-acute crisis text messaging outreach for suicide prevention. BMC Psychiatry. 2014;14:294. doi:10.1186/s12888-014-0294-8.

[26] Fleischmann A. Effectiveness of brief intervention and contact for suicide attempters: a randomized controlled trial in five countries. Bull World Health Organ. 2008;86:703-9.

[27] Bertolote JM, De Leo D. Global suicide mortality rates - A light at the end of the tunnel? Crisis. 2012;33:249-53.

[28] Cebrià AI, Parra I, Pàmias M, Escayola A, García-Parés G, Puntí J, et al. Effectiveness of a telephone management programme for patients discharged from an emergency department after a suicide attempt: controlled study in a Spanish population. J Affect Disord. 2013;147:269-76.

[29] Fleischmann A, Arensman E, Berman A, Carli V, De Leo D, Hadlaczky G, et al. Overview evidence on interventions for population suicide with an eye to identifying best-supported strategies for LMICs. Glob Ment Health. 2016;3:e5.

[30] Messiah A, Notredame C-E, Demarty A-L, Duhem S, Vaiva G, AlgoS Investigators. Combining green cards, telephone calls and postcards into an intervention algorithm to reduce suicide reattempt (AlgoS): post-hoc analyses of an inconclusive randomized controlled trial. PLoS One. 2019; 14:e0210778.

[31] Vaiva G, Walter M, Al Arab AS, Courtet P, Bellivier F, Demarty AL, et al. ALGOS: the development of a randomized controlled trial testing a case management algorithm designed to reduce suicide risk among suicide attempters. BMC Psychiatry. 2011;11:1. doi:10.1186/1471-244X-11-1.

[32] Duhem S, Berrouiguet S, Debien C, Ducrocq F, Demarty AL, Messiah A, et al. Combining brief contact interventions (BCI) into a decision-making algorithm to reduce suicide reattempt: the VigilanS study protocol. BMJ Open. 2018;8:e022762.

[33] Jardon V, Debien C, Duhem S, Morgiève M, Ducrocq F, Vaiva G. Un exemple de système de veille post-hospitalière des suicidants: VigilanS. L’Encéphale. 2019;45:S13-21.

[34] Fossi Djembi L, Vaiva G, Debien C, Duhem S, Demarty A-L, Koudou Y-A, et al. Changes in the number of suicide re-attempts in a French region since the inception of VigilanS, a regionwide program combining brief contact interventions (BCI). BMC Psychiatry. 2020;20:26.

[35] Inagaki M, Kawashima $\mathrm{Y}$, Yonemoto N, Yamada M. Active contact and follow-up interventions to prevent repeat suicide attempts during highrisk periods among patients admitted to emergency departments for suicidal behavior: a systematic review and meta-analysis. BMC Psychiatry. 2019;19:44.

[36] Exbrayat S, Coudrot C, Gourdon X, Gay A, Sevos J, Pellet J, et al. Effect of telephone follow-up on repeated suicide attempt in patients discharged from an emergency psychiatry department: a controlled study. BMC Psychiatry. 2017;17:96.

[37] Pushpakumara PHGJ, Thennakoon SUB, Rajapakse TN, Abeysinghe R, Dawson AH. A prospective study of repetition of self-harm following deliberate self-poisoning in rural Sri Lanka. PLoS One. 2019;14: e0199486.

[38] Kwok C-L, Yip PSF, Gunnell D, Kuo CJ, Chen YY. Non-fatal repetition of self-harm in Taipei City, Taiwan: cohort study. Br J Psychiatry. 2014;204: $376-82$.

[39] Rodante DE, Grendas LN, Puppo S, Vidjen P, Portela A, Rojas SM, et al. Predictors of short- and long-term recurrence of suicidal behavior in borderline personality disorder. Acta Psychiatr Scand. 2019;140: $158-68$. 
[40] Carter GL, Clover K, Whyte IM, Dawson AH, D'Este C. Postcards from the EDge: 24-month outcomes of a randomised controlled trial for hospitaltreated self-poisoning. Br J Psychiatry. 2007;191:548-53.

[41] Carroll R, Metcalfe C, Gunnell D. Hospital presenting self-harm and risk of fatal and non-fatal repetition: systematic review and meta-analysis. PLoS One. 2014;9:e89944.

[42] Larkin C, Di Blasi Z, Arensman E. Risk factors for repetition of self-harm: a systematic review of prospective hospital-based studies. PLoS One. 2014;9: e84282.

[43] Park S, Lee Y, Youn T, Kim BS, Park JI, Kim H, et al. Association between level of suicide risk, characteristics of suicide attempts, and mental disorders among suicide attempters. BMC Public Health. 2018;18:477.

[44] Ribeiro JD, Franklin JC, Fox KR, Bentley KH, Kleiman EM, Chang BP, et al. Self-injurious thoughts and behaviors as risk factors for future suicide ideation, attempts, and death: A meta-analysis of longitudinal studies. Psychol Med. 2016;46:225-36.

[45] van Orden K, Witte TK, Cukrowicz KC, Braithwaite SR, Selby EA, Joiner TE Jr. The interpersonal theory of suicide. Psychol Rev. 2010;117:575-600.

[46] Joiner T. Why people die by suicide. 1. Harvard University Press paperback ed. Cambridge, MA: Harvard University Press; 2007. Accessed 20 Oct 2020. https://scholar.google.com/scholar_lookup?title=Why+people+die +by+suicide\&author=T+Joiner\&publication_year=2007\&.

[47] Olfson M, Wall M, Wang S, Crystal S, Gerhard T, Blanco C. Suicide following deliberate self-harm. AJP. 2017;174:765-74.
[48] Centers for Disease Control and Prevention. Alcohol related disease impact (ARDI) application, www.cdc.gov/ARDI; 2013. Accessed 26 May 2020.

[49] Kaplan MS, Giesbrecht N, Caetano R, Conner KR, Huguet N, McFarland $\mathrm{B}$, et al. Acute alcohol consumption as a contributing factor to suicidal behavior. Am J Public Health. 2013;103:e2-3.

[50] Bagge CL, Lee H-J, Schumacher JA, Gratz KL, Krull JL, Holloman G Jr. Alcohol as an acute risk factor for recent suicide attempts: a case-crossover analysis. J Stud Alcohol Drugs. 2013;74:552-8.

[51] Borges G, Bagge CL, Cherpitel CJ, Conner KR, Orozco R, Rossow I. A meta-analysis of acute use of alcohol and the risk of suicide attempt. Psychol Med. 2017;47:949-57.

[52] Liu Y, Zhang J, Sun L. Who are likely to attempt suicide again? A comparative study between the first and multiple timers. Compr Psychiatry. 2017;78:54-60.

[53] Holma KM, Melartin TK, Haukka J, Holma IA, Sokero TP, Isometsä ET. Incidence and predictors of suicide attempts in DSM-IV major depressive disorder: a five-year prospective study. AJP. 2010;167:801-8.

[54] Léon C, Chan-Chee C, du Roscoät E. Et le groupe Baromètre de Santé publique France 2017. Baromètre de Santé publique France 2017: Tentatives de suicide et pensées suicidaires chez les 18-75 ans en France. Bull Epidémiol Hebd. 2019;3-4:38-47. Accessed 12 Jun 2020. http://invs. santepubliquefrance.fr/beh/2019/3-4/2019_3-4_1.html. 


\section{A. Appendix 1}

General variables

\begin{tabular}{|c|c|}
\hline Age & Age at entry into Viglans \\
\hline $\begin{array}{l}\text { Geographic subregion (French } \\
\text { "Departement") }\end{array}$ & Department in which the patient lives (Nord, Pas-de-Calais, others) \\
\hline Date of SA & Date of the patient's SA when entering ViglanS \\
\hline Year VigilanS’ entry & Year of the patient's SA when entering ViglanS \\
\hline Alcohol consumption & If the patient consumes alcohol regularly on a daily basis (Yes/No) \\
\hline Accompanying person & Whether the patient has a companion with him/her during the emergency room visit (Yes/No) \\
\hline Hospitalization stay & Length of time spent in hospital following a SA (0 day, 1 day, 2 days, or more) \\
\hline D10-D21 call successful & If calls made at D10-D21 were successful (Yes/No), for non-primary suicide attempters \\
\hline Intermediate calls received (Incoming call) & $\begin{array}{l}\text { Number of intermediate calls received: This is the number of intermediate calls received during the follow-up (0 } \\
\text { received call, } 1 \text { received call, or more) }\end{array}$ \\
\hline Intermediate calls made to the entourage & $\begin{array}{l}\text { Number of intermediate calls made to the entourage: This is the number of calls made to the entourage during the } \\
\text { follow-up ( } 0 \text { call made, } 1 \text { call made or more) }\end{array}$ \\
\hline Calls received from the entourage & $\begin{array}{l}\text { Number of calls received from the entourage: This is the number of calls received from the entourage during the } \\
\text { follow-up ( } 0 \text { call received, } 1 \text { received or more) }\end{array}$ \\
\hline Means of suicide attempt used & $\begin{array}{l}\text { This is the type of means used by the patient to carry out his SA (voluntary drug intoxication or vdi, hanging, } \\
\text { phlebotomy, others) }\end{array}$ \\
\hline Suicide reattempt & Whether or not the patient has had a suicide attempt recurrence (Yes/No) \\
\hline
\end{tabular}

\section{B. Appendix 2}

Variables at D10-D21 phone call (non-primary suicide attempters)

\begin{tabular}{ll}
\hline Evolution of the discomfort & $\begin{array}{c}\text { Evolution of the discomfort from the time of entry into Viglans until the time of the call D10-D21 (stationary, favorable, } \\
\text { unfavorable) }\end{array}$ \\
\hline Patient's state & Patient's state at the end of the interview D10-D21 (fine, in difficulty, in crisis) \\
\hline Need for help & Whether the patient needed help during this call D10-D21 (Yes/No) \\
\hline $\begin{array}{l}\text { Follow-up by a Psychiatrist in } \\
\text { progress }\end{array}$ & If the patient is being followed by a Psychiatrist outside ViglanS program (Yes/No) \\
\hline
\end{tabular}


C. Appendix 3

Residuals from the initial model with the variable "Year"
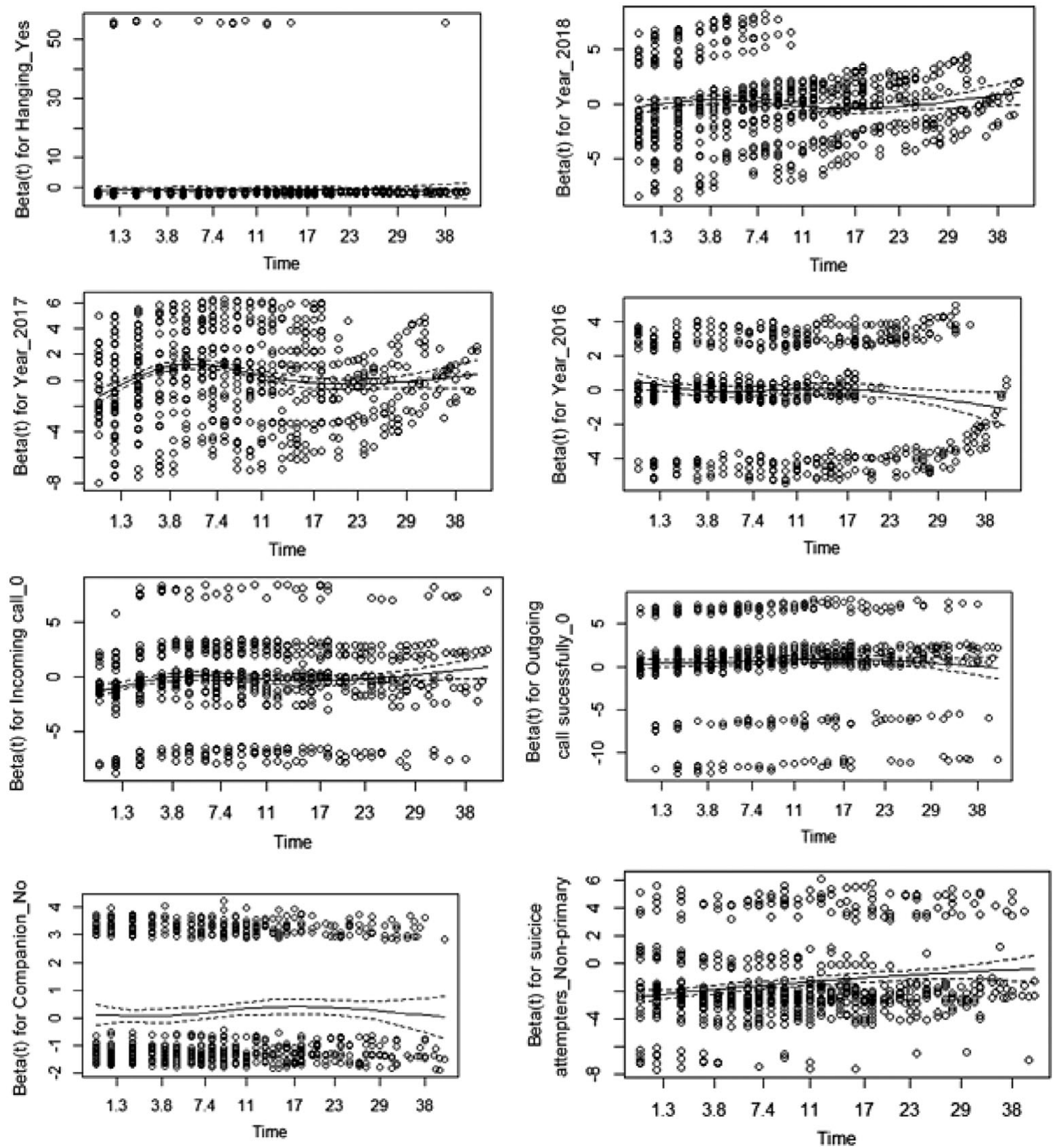

The effect of the variable "Year VigilanS' entry" increases linearly with time, unlike the other variables. 
D. Appendix 4

Final model (residuals from the final model without the variable "Year VigilanS' entry")
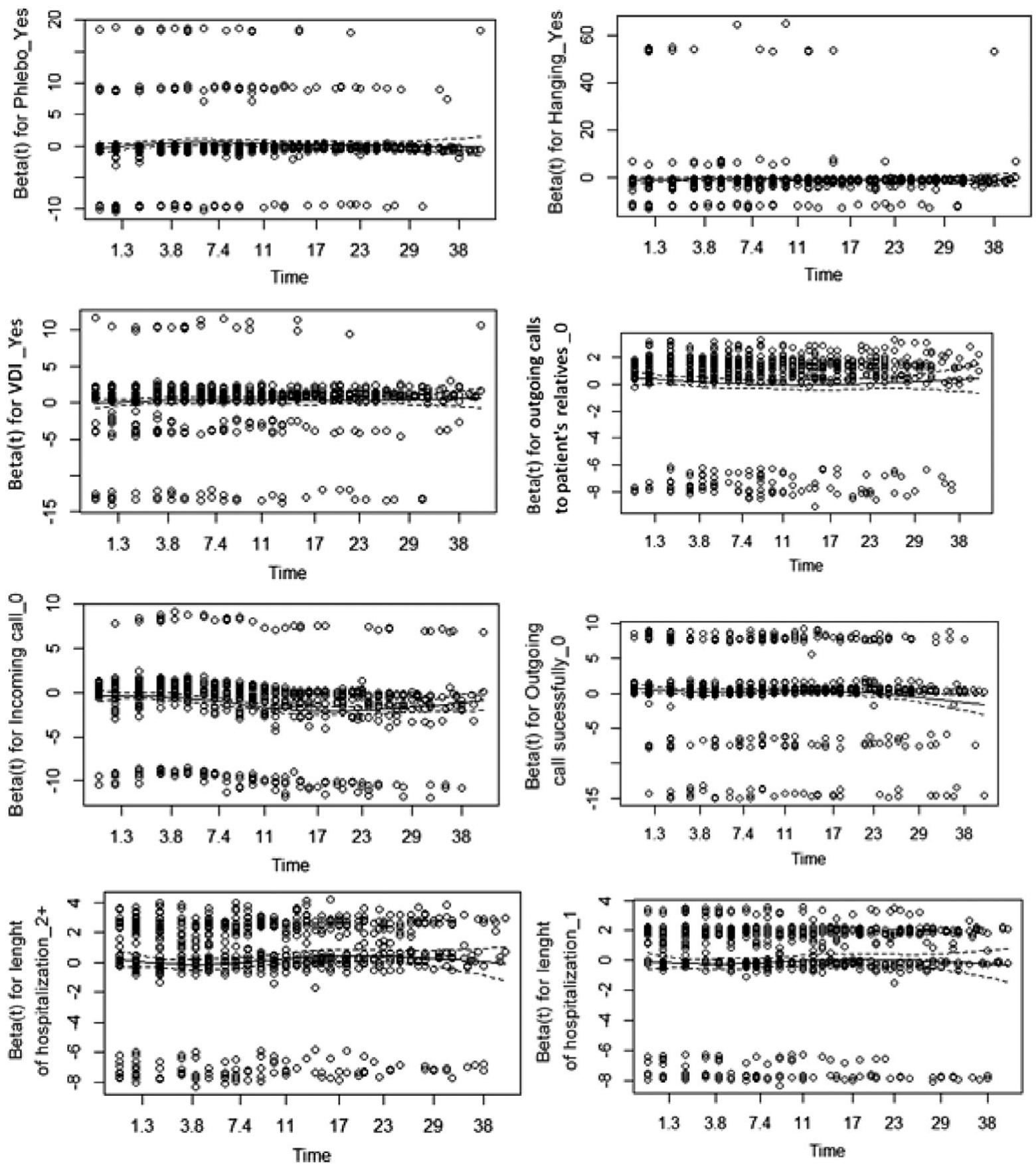

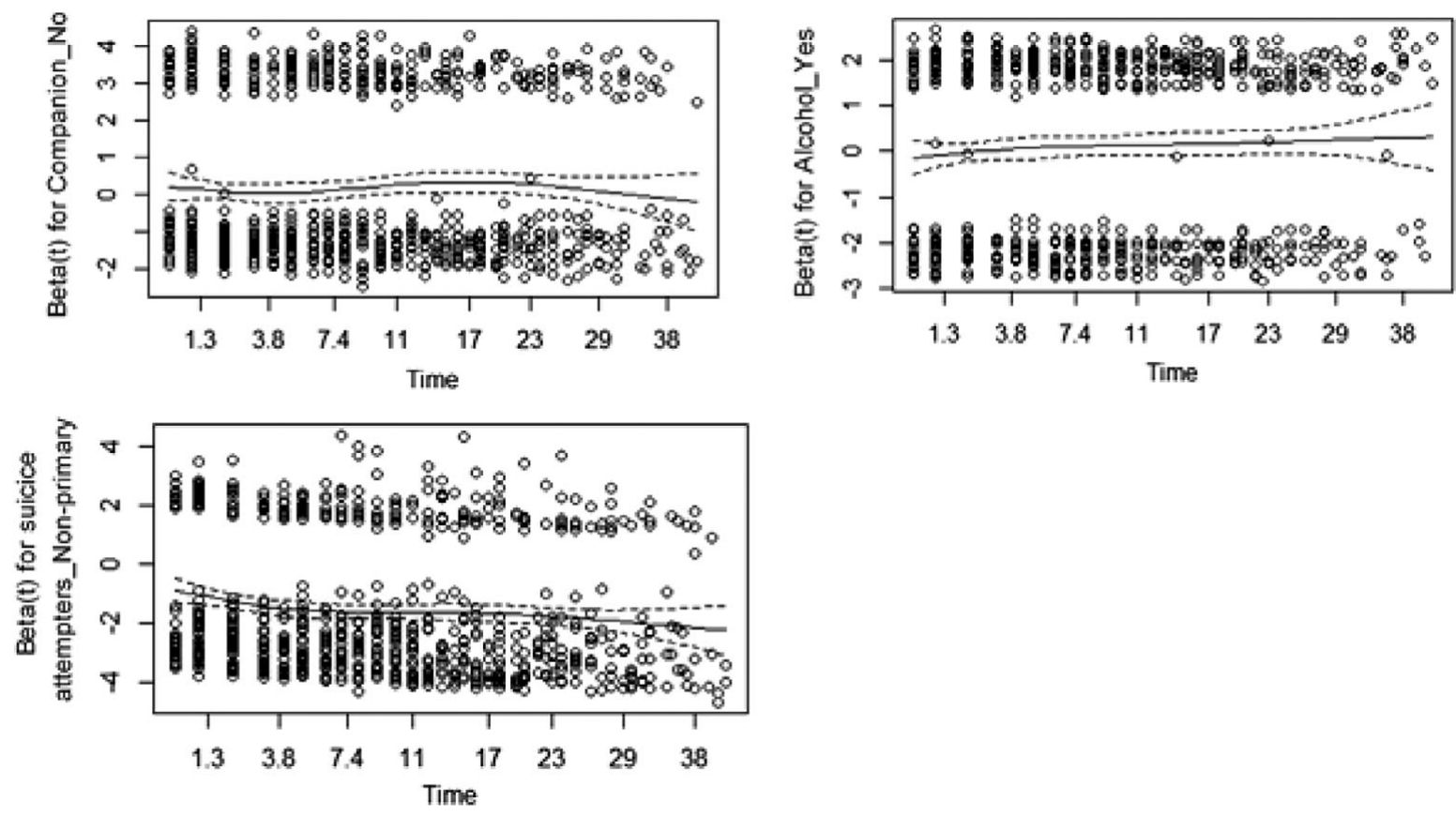

The other effects appear fixed. 